\title{
Religious authority and the transmission of abstract god concepts
}

\author{
Forthcoming in Philosophical Psychology
}

\author{
Nathan Cofnas \\ Balliol College, Oxford \\ nathan.cofnas@balliol.ox.ac.uk
}




\begin{abstract}
According to the Standard Model account of religion, religious concepts tend to conform to “minimally counterintuitive” schemas. Laypeople may, to varying degrees, verbally endorse the abstract doctrines taught by professional theologians. But, outside the Sunday school exam room, the implicit representations that tend to guide people's everyday thinking, feeling, and behavior are about minimally counterintuitive entities. According to the Standard Model, these implicit representations are the essential thing to be explained by the cognitive science of religion (CSR). It is argued here that this theoretical orientation of mainstream CSR misses a whole dimension of religiosity — the acceptance of certain religious authorities, that is, the acceptance of other people's superior expertise. Average believers (especially in doctrinal traditions) tend to accept the authority of religious experts who espouse highly counterintuitive ideas that they (the laypeople) understand in a distorted form, if at all. These highly counterintuitive ideas are culturally successful because laypeople see them as being justified by people they have reason to regard as epistemic authorities. The tendency for people to endorse (without fully understanding) highly counterintuitive religious ideas espoused by intellectuals may explain parallels in the development of separate traditions (e.g., Judaism and Hinduism), as religious philosophers follow parallel lines of reasoning.
\end{abstract}

Keywords: cognitive science of religion; Standard Model theory of religion; Mickey Mouse problem; Zeus problem; cultural transmission 


\section{Mainstream cognitive science of religion: The "Standard Model"}

The Talmud is 5,422 pages of dense argumentation about religious law and philosophy. Aquinas's Summa Theologica contains extensive discussion of 631 questions, divided into thousands of sub-questions, at the heart of Christianity. The foundational texts of Hinduism—the Vedas and the Upanishads—are supplemented by a mind-boggling body of commentaries. Needless to say, only a tiny fraction of this information makes its way into the mind of the average Jew, Catholic, or Hindu.

Mainstream cognitive science of religion (CSR) is not interested in the theological minutiae that occupy theologians and seminary students. It is the science of what makes it into the brains of typical believers and arouses real-life passion. It seeks to identify the neurocognitive mechanisms that underlie actual religious representations and reasoning. In giving an evolutionary account of these mechanisms, cognitive scientists seek to explain religion. If it turns out that the mechanisms originally evolved for purposes unrelated to religion (the dominant view), then religion is a byproduct of our evolved psychology (Atran \& Henrich, 2010; Boyer, 2003). If it turns out that they evolved specifically because they gave rise to religious belief, then religious belief is itself an adaptation to perform some yet-to-be-identified function (Bulbulia, 2004).

The "Standard Model" (SM; Boyer, 2005) account of religion, which is, as its name suggests, the standard account given in CSR, holds that religion is a byproduct. According to the SM, propositions formulated in certain ways resonate with our minds and tend to be believed by us. Specifically, we have innate assumptions about different kinds of objects and agents, and a disposition to believe in entities (real or imaginary) whose nature violates our expectations in one 
or two respects, and which meet certain other basic criteria. As Atran (2002) writes: “All religions...involve counterintuitive beliefs in supernatural beings. Moreover, such beliefs are systematically counterintuitive in the same basic ways....[T]hese basic ways of entertaining supernatural beliefs are more or less predictable from a fairly limited set of species-specific cognitive structures” (p. 9). And Barrett (2004): “Our minds tend to consider and believe in agents that have a limited set of superhuman properties” (p. viii; italics added).

The normal human mind, the SM says, is endowed with innate templates representing different ontological categories. The templates determine our assumptions concerning (a) biology, (b) psychology, and (c) physics about objects that are classified as being in a specific category. For example, if $X$ is an animal, we assume, among other things, that $X$ s are produced by other $X \mathrm{~s}$, and $X$ s react to the environment and move around. The ANIMAL template indicates possible and impossible ways in which various animals may differ from each other. Five ontological categories have been identified as playing a role in religion: (a) HUMAN, (b) ANIMAL, (c) PLANT, (d) ARTIFACT, and (e) NATURAL OBJECT (Atran, 2002, p. 98; Barrett, 2000, p. 31; Boyer, 2001, p. 78). Entities that violate, in one or two respects, the expectations dictated by these templates are termed “minimally counterintuitive” (MCI). Propositions that most resonate with us and are best remembered—and are therefore likely to be transmitted from person to person or generation to generation-are those that describe MCI objects and agents (Banerjee, Haque, \& Spelke, 2013; Barrett \& Nyhof, 2001; Boyer \& Ramble, 2001; Norenzayan, Atran, Faulkner, \& Schaller, 2006), while also engaging other inference systems (Atran, 2002; Barrett \& Lanman, 2008; Boyer, 2001). Such entities are more noteworthy to our minds than those that are merely unusual. People are more likely to remember that there was "a table...that felt sad when people left the room” than that there was "a 
table made of chocolate.” The former proposition ascribes emotions to an artifact, violating our innate assumptions; the latter describes a kind of artifact—table—made out of an unusual material—chocolate—but without violating our innate assumptions about objects classified in that ontological category (Boyer, 2001, p. 80; see Atran, 2002, pp. 101-107).

Recently, scholars of CSR have questioned whether MCI concepts are as pervasive in religion as the SM supposes. Purzycki and Willard (2016), for example, argue that SM theorists often use overly liberal criteria for identifying beliefs as MCI, and that most religious concepts may be generally attention-grabbing/surprising rather than specifically MCI (see also Willard, Henrich, \& Norenzayan, 2016). Many religious entities designated by SM theorists as MCI may violate culturally relative schemas formed in individuals' lifetimes rather than universal and innate assumptions (Russell \& Gobet, 2013). The present paper reiterates and expands on the concern that religious concepts are often not MCI. It proposes an explanation for why, under certain conditions, highly counterintuitive religious concepts become more successful than simpler, more memorable, and more intuitive ones (whether those simpler concepts are MCI, intuitive, or merely surprising). In general, it is argued that people tend to adopt and transmit beliefs that they see as being explanatorily powerful while at the same time being logically consistent with other beliefs to which they are committed. Sometimes people see beliefs as justified because they are espoused by credible authorities. Under conditions that conduce to “doctrinal mode” religion (Whitehouse, 2002, 2004), theologians develop highly counterintuitive but more or less logically consistent religious doctrines. These doctrines are "highly counterintuitive" in the sense that they require the sustained application of effortful, System 2 reasoning processes in order to be developed or learned. People come to accept the expertise of theologians, and accept their abstract ideas even without fully understanding them. 
Section 2 critically analyses two purported discoveries that are at the heart of the SM, and which are used to justify the claim that the most successful god concepts are MCI. These are: (1) People who claim to believe in highly counterintuitive religious entities implicitly represent them as MCI agents; (2) the beliefs of theologians are radically different from-and have little relevance for - the beliefs of laypeople, which center on MCI agents. Section 3 examines the socalled Mickey Mouse problem and the Zeus problem: Why, if people are disposed to believe in MCI agents, do they fail to believe in Mickey Mouse or (nowadays, at least) Zeus? In response to Mickey Mouse-type problems, Barrett (2008) proposes four criteria besides minimal counterintuitiveness that a god concept must possess in order to be successful (i.e., to be believed in, to elicit commitment, and to be transmitted from person to person). Examination of his discussion shows that in the end he resorts to commonsense explanations for why people disbelieve in entities like Mickey Mouse or Santa Claus—namely, because evidence does not support their existence. The four criteria are not sufficient to make god concepts successful, and so do not have the special explanatory power claimed for them by Barrett. Henrich’s (2009) claim that religious beliefs must be espoused by prestigious individuals who demonstrate “credibility enhancing displays” (CREDs) may be true, but it also does not solve the Mickey Mouse/Zeus problem, since it does not fully explain why people choose to follow certain CREDexhibiting prestigious individuals rather than others. The final section reexamines the two tenets of the SM discussed in Section 2 in light of the discussion in Section 3, arguing that the (explicit) beliefs that people transmit to each other are highly counterintuitive, and laypeople accepting the authority of (perceived) religious experts is an essential aspect of religious belief and behavior. This conclusion is used to explain parallels in the God concepts of Judaism and Hinduism. 


\section{Two tenets of the SM}

The SM is grounded on two essential tenets (Barrett, 2007, p. 769, describing them somewhat differently, identifies them as "two prominent findings of the field"). The first is that individuals' implicit religious representations are different from their explicit representations (e.g., Atran, 2002; Barrett, 1998, 1999; Barrett \& Keil, 1996; Boyer, 2001). ${ }^{1}$ During formal religious education, usually in childhood (in Sunday school or the like), laypeople learn some of the abstract tenets of their religion. Christians learn, for example, that God is omnipotent and omniscient, that time itself is part of the creation, that God stands outside the world, and so on. If you administer a theology test to Sunday school-educated Christians asking questions like "Does God know everything?” or “Can God do only one thing at a time?” they repeat the answers they were taught (in this case, yes and no). But theology tests only tap into explicit representations which (according to the SM) exist largely independently of more intuitive-implicit— representations that determine religious thought and feeling in everyday situations, and which underlie actual religious passions. To find out how people implicitly represent or reason about religion, you have to ask them questions under time pressure, high cognitive load, or other situations where they cannot, or are not inclined to, access the information (from semantic memory) that they memorized for Sunday school exams.

Essentially the only evidence cited in support of this is a series of studies conducted by Barrett and Keil (see, e.g., Atran, 2002, p. 94; Atran \& Henrich, 2010, p. 20; Boyer, 2001, p. 88; Dennett, 2006, p. 131; Lawson, 1999, p. 721; Norenzayan et al., 2006, p. 534). Barrett and Keil

\footnotetext{
${ }^{1}$ These claims only apply to followers of doctrinal religions like Christianity.
} 
(1996) and Barrett (1998) argued that when college students in the United States and India heard or read vignettes describing God acting supernaturally, they interpreted God as acting anthropomorphically. For example, if God was described as answering two prayers at once in different parts of the world, subjects remembered him as answering the prayers sequentially, as if he were subject to the same constraints as people. ${ }^{2}$ They concluded that although Christians and Hindus may explicitly represent God as having many supernatural properties, their implicit representation of him, which they employ in actual day-to-day religious reasoning, is highly anthropomorphic (and MCI).

The second tenet of the SM is that while theologians might invent highly abstract God concepts, “[t]heological ideas that exceed [the MCI] cognitive optimum [are] likely [to] be distorted or ignored” (Barrett, 2007, p. 772; citing Boyer, 2001; Slone, 2004). On this view, priestly castes in literate societies produce complex religious ideas, generally in order to reinforce their monopoly on religious services. Though laypeople might profess to believe in some of the teachings of the priests, they do not generally understand them (see Boyer, 2001, pp. 158, 278-285). Priests know a lot more about religious traditions than children learn, let alone remember, in religious school. The average believer can aver that "God can do anything.” A

\footnotetext{
2 There is some concern that the vignettes used in Barrett and Keil's studies themselves contained anthropomorphism (Pyysiäinen, 2012, p. 35; Shtulman, 2008, p. 1125). Subjects may have correctly interpreted the anthropomorphic descriptions rather than wrongly introduced them. That issue is outside the scope of this paper.
} 
theologian presumably knows the paradoxes generated by that proposition, ${ }^{3}$ and has some way of answering them. And the theologian presumably knows about all sorts of recondite doctrines that the layperson has never heard of. SM theorists emphasize that specialist theological traditions exist only in advanced, literate cultures — they are not a human universal—and in cultures where they do exist only a small percentage of people are versed in them (Atran, 2002; Boyer, 2001).

These two tenets are related because laypeople's explicit beliefs/representations are influenced by the teachings of "literate theologians” (Boyer’s term). The simplified slogans that the folk know about their religious doctrines come from the priestly caste. The information gets systematically distorted (due to cognitive biases) when it passes from theological scholars through low-level teachers down to children or lay adults. Still, laypeople (in literate cultures) acquire some explicit knowledge of complex doctrines, and this knowledge is developed and disseminated by the religious intellectual elite.

The SM treats the implicit representations that (supposedly) guide laypeople’s actual thinking, behavior, and feeling as the important thing to be explained. It sees as sideshow phenomena the rarified theological debate and official religious doctrines that laypeople either do not know about or verbally endorse but do not actually care about. Many cognitive psychologists dismiss believers’ explicit theological beliefs as mere "theological correctness” (Barrett, 1999, 2007; Boyer \& Bergstrom, 2008), which “doesn’t determine people’s actual thoughts and behaviors” (Slone, 2004, p. 4).

But focusing only on the implicit, or even explicit, representations and beliefs about God

\footnotetext{
${ }^{3}$ E.g., can God learn something new? Or — the most famous one-can God make a stone too heavy for him to lift?
} 
in people’s heads misses an important aspect of their relationship to religion. Namely, most seriously religious people believe in the authority of religious experts. They believe that the religious experts know better than they do, and they often defer to their judgments about what to do. Compare the (explicit) beliefs of laypeople about religion to their beliefs about physics or biology. The average nonexpert's beliefs about physics and biology are systematically wrong, sometimes even after extensive exposure to true beliefs (Shtulman, 2017). Nevertheless, most nonexperts accept the authority of physicists and biologists, at least in nonpoliticized domains. Nonexperts may hold incorrect beliefs, but they acknowledge that, insofar as their views differ from those of experts, it is the experts who are right. When a collective decision must be made about how to fix a bridge or what building codes to establish, people defer to others whom they perceive to be epistemic authorities. If you gave random Catholics a theology test, you would probably discover as much ignorance as you would if you gave random non-physicists a test about physics. In both cases, you would be overlooking the belief of the test takers that some authorities know better than they do. By studying only the representations of God that people reveal implicitly, or even report explicitly, CSR misses a whole dimension of religiosity—-the acceptance of certain authorities and the rejection of others. ${ }^{4}$

\footnotetext{
${ }^{4}$ Religious and scientific authority are undoubtedly established in different ways, reflecting the difference between religion and science. Scientific authority is—or is supposed to be-grounded in the ability to make verifiable predictions. Religious authority is grounded in a perceived relationship with the divine or with mastery of religious principles. Still, there is a deep parallel in the way laypeople relate to religious vs. scientific authorities. A layperson who accepts a religious or scientific authority thereby holds that the authority’s beliefs about religion or
} 
There is another problem with focusing only on believers’ implicit representations. The SM is supposed to be a theory about what religious ideas are transmitted, not just about how religious ideas are implicitly represented. MCI concepts are supposed to have a transmission advantage. But only verbally articulated, explicit representations can be transmitted. As shall be discussed, even if religious concepts are implicitly represented as MCI, there is reason to think that many of the most successful god concepts that are transmitted from person to person are in fact highly counterintuitive (cf. Whitehouse, 2004).

\section{What makes god concepts successful? The Mickey Mouse problem and the Zeus problem}

What religious beliefs people adopt cannot be a simple function of the content of the beliefs to which they are exposed, as SM theorists have acknowledged. Most everyone is exposed to the ideas of the Christian God and to Zeus. Eighteen hundred years ago some people believed in the former and some in the latter. Today, many people believe in the Christian God and practically no one takes the existence of Zeus as a serious possibility. Gervais and Henrich (2010) call this the "Zeus Problem.”

The "Mickey Mouse problem” is almost as old as the SM itself-to SM theorists it has been seen as the major challenge for their theory. Atran recounts posing this problem at a conference in 1999. Cognitive scientists like Barrett, Boyer, and Lawson outlined the basic premises of what came to be known as the SM. In Atran's (2002) words:

science, respectively, are more reliable than what they themselves are able to report in a survey or on a test. 
They offered new data and interpretations for a convincing view of religion, namely, as a family of cognitive processes to produce minimally counterintuitive worlds that are attention-arresting, hence readily memorable and liable to cultural transmission, selection, and survival. But to the question I posed- "How, in principle, does this view distinguish Mickey Mouse from God, or fantasy from beliefs one is willing to die for?”there was acknowledgment that nothing in the cognitive literature at the time offered an answer. (p. x)

The Mickey Mouse problem raises two questions at once: Why do we fail to believe in, and why do we fail to become committed to, some MCI entities? The commonsense answer to the former is that no one is tempted to believe in Mickey Mouse because he is explicitly presented as a fictional entity. When Mickey Mouse is depicted in cartoons, an explicit message appears declaring that he is a character imagined (not brought into existence) by Walt Disney and Ub Iwerks. There is also a commonsense answer to the latter question. Just as we do not typically believe in something without evidence (broadly construed), we do not commit ourselves to something without reason—-the thing in question must be perceived as making a difference to our lives. Even if there were compelling evidence to believe that Mickey Mouse existed, it is unlikely that Mickey Mouse believers would be committed to him in the sense that they would “willingly sacrifice even their lives to uphold” this belief (to use Atran’s, 2002, p. 14, expression).

Some of the entities and phenomena discovered or described by science are MCI in the 
technical sense of violating innate ontological templates ${ }^{5}$ in one or two respects (cf. Barrett, 2008, p. 151, n. 1). For example, magnets are physical objects (or artifacts) that can be moved without touching them. Magnets are MCI objects that actually exist and in which practically everyone believes, but people are not normally passionately committed to magnets.

People seem to become passionate about their beliefs—in MCI religious entities, scientific phenomena, straightforward intuitive phenomena, or even highly counterintuitive entities - when they see their welfare (in this life or the next) as being tied to those beliefs. Religious Catholics may be passionate about belief in the Trinity because (leaving caveats aside) they think that holding this belief is required to go to heaven. (The notion that the Trinity and the Abrahamic God are MCI concepts, as SM theorists claim [see, e.g., Boyer, 2001], will be questioned later.) At issue is whether the SM can explain why religious beliefs elicit passion without resorting to the commonsense fact that people care about things that make a difference to them.

Atran (2002) concludes that "purely cognitive” theories of religion are insufficient because they are "motiveless" (p. 264). They need to be supplemented, he says, with theories about why we believe in some MCI entities and not others, and what makes us committed to such entities. Barrett acknowledges that being MCI is not enough to be a successful god concept, and offers a supplementation to the SM of the sort Atran called for:

[S]uccessful god concepts...must be (1) counterintuitive, (2) an intentional agent, (3) possessing strategic information, (4) able to act in the human world in detectable ways

\footnotetext{
${ }^{5}$ Assuming such ontological templates exist with the properties ascribed to them by the SM.
} 
and (5) capable of motivating behaviors that reinforce belief. [Because] Santa Claus appears to be only inconsistently represented as having all five requisite features Santa has failed to develop a community of true believers and cult. (Barrett, 2008, p. 149)

However, Barrett continues, Santa's cultural prominence is a consequence of the Santa concept "approximat[ing] a successful god concept more closely than other widespread cultural characters such as Mickey Mouse.”

According to Barrett, on the surface Santa is MCI (a flying person), an intentional agent, he possesses strategic information (about whether you have been bad or good), his acts (leaving presents) are detectable, and he motivates reinforcing behaviors (children leave out milk and cookies for him). “[O]n closer examination,” Barrett says, "Santa’s failure as a god may come from the fact that [he] is variably represented across individuals such that he fails to satisfy all of the criteria.” He claims that, in films, Santa is often represented not as a (minimally) counterintuitive being, but as a regular person who uses magic. Barrett informally surveyed 12 American university students and found that "only six unambiguously attributed to Santa a counterintuitive property (five mentioned his immortality, four attributed counterintuitive knowledge)" (p. 155). Santa may know whether people are morally good or bad "on balance," but possessing strategic information involves "knowing whether someone has done or plans to do a particular morally bad or good act," and neither "popular media” nor the 12 survey participants clearly represent Santa as having this information. Although Santa is represented as acting in the world in detectable ways, this activity is restricted in time, place, and form, in comparison with successful god concepts, which typically postulate gods that act throughout the year in a variety of ways. The behaviors that the Santa concept motivates to reinforce belief are 
similarly restricted in time- - to "one annual visit” (p. 157).

In the end, Barrett acknowledges that belief in Santa may fail to take hold in part because his "alleged activities...may be more simply explained by appealing to parents instead of Santa" (p. 157). This is presumably true, but Barrett is just resorting to the commonsense explanation of disbelief in Santa, namely, people disbelieve in him because they know he is made up and that the evidence for his existence (presents under the tree, disappearing cookies) is planted. He also notes that, at a certain point, children realize that visiting every household with children on one night is "impossible," at least for a human. But why do children not just assume that Santa possesses the necessary "counterintuitive" properties that would allow him to accomplish this feat- the same way they (often) conclude that God, which, according to Barrett, we represent anthropomorphically as an MCI person (Barrett \& Keil, 1996), possesses the counterintuitive properties that allow him to perform the actions attributed to him? Besides counterintuitiveness/minimal counterintuitiveness, the other four criteria that Barrett claims a god concept must satisfy in order to be successful turn out to be roundabout ways of saying that people care about things that make a difference to their lives (i.e., things that affect them and influence their behavior). While this may be true, it pushes the explanatory problem back to the question of how people form judgements about what is plausible or supported by evidence.

So let us turn to that question—how do people form judgments about what is "plausible" or "supported by evidence"? On the one hand, in certain domains and contexts people systematically adopt false beliefs. Our procedures for assessing beliefs as plausible are not scientific (Knobe, 2010; Shtulman, 2017). On the other hand, not all of our intuitively formed beliefs are false. Our intuitions responsible for belief formation do guide us toward the truth in some contexts, and often protect us against accepting blatant lies. 
Shtulman (2017) notes that one of the three "hallmarks" of our intuitive (i.e., nonscientific) theories is that they are "coherent," embodying "a logically consistent set of beliefs and expectations” (p. 10). Even though people hold incorrect views about, for example, physics, they reason about physics (from false premises) more or less consistently. The fact that untrained people do not reason in the same way as scientists does not mean that they hold obviously contradictory views, or that there is no internal logic to their understanding of how things work. A study cited by Shtulman provides a nice illustration of this in children. In the "tubes task," winding tubes emanate from buckets so that the top of each tube stands directly over a bucket, but not the one to which it itself is connected. Thus, the top of the tube connected to bucket A may be positioned directly over bucket B or C. If you ask children younger than four in which bucket a ball dropped in a certain tube will fall, they say that it will fall into the bucket directly underneath the top of the tube, thereby demonstrating a "gravity error." However, if toddlers see where the ball fell themselves, or if they have attained understanding of how the apparatus actually works, they cannot be "talked into making a gravity error” (Shtulman, 2017, p. 68; citing Jaswal, 2010). In their analysis of how children learn through testimony, Harris and Koenig (2006) note that very young children "rework what they are told so as to arrive at a coherent conceptualization” (p. 508).

Even very young children do not passively receive testimony from normally trusted sources/epistemic authorities. They actively try to incorporate the testimony they receive into a coherent causal picture. If the testimony cannot be thus incorporated then it may be simply rejected. In regard to belief in Santa, the reality of Santa is affirmed by bona fide epistemic authorities (e.g., parents) and Santa's existence explains some observable phenomena (presents and eaten cookies). When children learn that it is their parents who left the presents and ate the 
cookies, the proposition that parents lied about Santa becomes the only explanation that accounts for all the data the child seeks to explain. The value placed on consistency in our beliefs manifests early in life.

To solve the Mickey Mouse/Zeus problem, Henrich (2009) postulates an innate learning bias underlying cultural transmission. Humans acquire a great deal of crucial adaptive information by cultural learning. In order to extract information that is most likely to lead to adaptive outcomes, we have evolved biases that make us learn selectively. Chief among these biases are a tendency to copy successful rather than unsuccessful individuals, and to adopt the beliefs of the majority rather than the minority (Henrich, 2016; Richerson \& Boyd, 2005). Henrich (2009) notes that our tendency to learn from successful or prestigious individuals, combined with our linguistic abilities, leaves us vulnerable to exploitation. At no cost to themselves, successful/prestigious people can falsely express beliefs that, when adopted by others, harm the learners but benefit the teachers (e.g., "The ancestors speak through me and they want you to...”). To protect ourselves from exploitation, we have, Henrich suggests, evolved to selectively learn from prestigious people only when their espoused beliefs are accompanied by “credibility enhancing displays” (CREDs). CREDs are actions that the espouser of a belief would be unlikely to perform unless their belief was sincere.

Henrich argues that people's demand for CREDs could explain why many religions place so much emphasis on martyrs, and why religious authorities in many traditions engage in conspicuous acts of self-deprivation such as fasting and celibacy. He cites evidence that the public torture and executions of Christians in ancient Rome, for example, played an important role in inspiring converts.

On Henrich’s view, Mickey Mouse could become a God if belief in him were associated 
with CREDs in "prestigious individuals or large groups," especially by models of the same sex and ethnicity as the learners. He says: "From the perspective of a learner, the difference between Mickey and Yahweh, or Yahweh and Zeus, is that learners observe members of their social group, including their chosen models, performing CREDs” (p. 258).

The demands for CREDs are surely a real phenomenon, and it quite probably explains important aspects of religion like the significance of martyrs and priestly celibacy. Still, as an answer to the Mickey Mouse/Zeus problem, it faces some of the same issues as Barrett's proposed answer. Henrich says that some people believe in Yahweh but not cartoon characters or ancient Greek Gods because “members of their social group, including their chosen models,” perform CREDs. But how do people, both as individuals and as groups, choose their models?or even their groups? The Christians who were martyred in the colosseum in ancient Rome were the opposite of prestigious, they were not the only people willing to sacrifice themselves for their religious beliefs, initially they were a small minority, and many of them were perceived as belonging to a different ethnicity than the Romans they inspired to convert. Their willingness to sacrifice themselves might have contributed to the success of Christianity, but that cannot be the only factor. Consider a prestigious person in the United States whom many people have chosen as a model: Christian evangelist Pat Robertson. If Pat Robertson converted to Catholicism, he would surely loose many of his followers, though, if he were convincing enough, some of his followers would probably convert with him. (The very act of becoming a Catholic might be a CRED for Robertson, since he would thereby be hazarding his established power, reputation, and legacy.) If he converted to Mickey Mouse or Zeus worship, even if his conversion were accompanied by CREDs that left no doubt about his sincerity, he would presumably be rejected as a model by practically everyone. Prestige and CREDs are important cues that direct people to 
consider copying potential models, but it is clear that the presence of these cues is not sufficient to trigger cultural transmission. Otherwise ancient Romans would not have copied the martyred Christians who were of low prestige and generally of a different ethnicity (i.e., Jewish).

\subsection{Is minimal counterintuitiveness necessary?}

The minimal counterintuitiveness criterion claims that religious propositions must conform to a certain schema (i.e., an MCI one) to maximize their chance of success. According to Barrett (2008), although theoretically the objects of religious belief could have many highly counterintuitive properties, “[i]n practice, a large number of counterintuitive properties undermines conceptual structure to the point that it lacks coherence and might no longer qualify as a concept” (p. 151). He asks us to compare an MCI concept with a highly counterintuitive one: an "invisible buffalo" vs. "an invisible buffalo that is immortal, made of steel, experiences time backwards, fails to exist on Saturdays, gains nourishment from ideas, and gives birth to kittens.” He offers the former (MCI) concept as a "strong candidate[] for successful spread,” whereas the latter (highly counterintuitive) one is just "a list of attributes instead of a coherent concept.”

What exactly does Barrett mean when he says that the invisible buffalo is a stronger candidate for "successful spread," or for a "successful god concept," than the buffalo with many counterintuitive properties? In fact neither concept seems to be part of any religion. ${ }^{6}$ Our

\footnotetext{
${ }^{6}$ Belief in something like buffalo spirits may be part of some Native American traditions, but these can be distinguished from buffaloes that simply cannot be seen.
} 
intuition that an invisible buffalo is more likely to be a part of a religion than the one that is invisible, immortal, made of steel, etc. might not be due to the fact that MCI concepts resonate with or sound more plausible to us. An alternative explanation is that we could more easily imagine a religious system in which invisible buffalos might serve an intelligible purpose: Maybe they guard the plains from evil spirits, or serve as food for dead hunters. That is, invisible buffalos strike us as “candidates” for spread because we can imagine their existence being justified in a religious system. The other, highly counterintuitive buffalo contains some properties that might not make sense at all (“experiences time backwards”), or that do not make sense without explanation (most of the rest of the properties). In contrast with the merely invisible buffalo, it is practically impossible to imagine a function that the highly counterintuitive buffalo might play in a religious system.

In other words, to illustrate the idea that MCI concepts are more plausible candidates for religious/god concepts than highly counterintuitive ones, Barrett compares (here and elsewhere) a simple MCI concept that could easily be imagined to play an intelligible role in a religious system, and a highly counterintuitive concept whose counterintuitive properties are random, incoherent, or potentially contradictory. The MCI concept seems like a better candidate for belief. But is it because it is MCI? To test the SM account of religion we should compare MCI concepts with highly counterintuitive concepts that are equally coherent. If we do that, it is easy to come up with highly counterintuitive concepts that are much better candidates for successful transmission than some MCI ones. For example, the Islamic God has many counterintuitive properties: omniscience, omnipotence, omnipresence, lack of a physical body, and so on. An “invisible potato”- to use another of Barrett’s (p. 152) examples—has only one. Yet 23\% of people on earth (ostensibly) believe in the Islamic God, another 33\% believe in a similarly 
described Christian God, and no one believes in an invisible potato although Barrett claims that “an invisible potato is a good candidate for a god concept” (p. 152).

This brings us back to the two fundamental tenets of the SM- "two prominent findings of [CSR]” (Barrett, 2007, p. 769)—discussed in Section 2. SM advocates will say that (1) religious Christians and Muslims do not implicitly represent God as a highly counterintuitive agent, but as an MCI one, and (2) even the more counterintuitive, “theologically correct” (Barrett, 1999, 2007) explicit representations of God held by typical believers are significantly simplified and distorted versions of the abstract, sophisticated God concepts held (explicitly) by theologians. Even if we accept this, we are still faced with the fact that the most successful God concepts — at least the most successful explicit God concepts—are nothing like "invisible potatoes" (or invisible potatoes that also meet the other four criteria that Barrett claims make for a successful god concept — e.g., an invisible potato that magically punishes people for moral transgressions or if they fail to perform daily sacrifices to it). SM theorists argue that we implicitly represent religious entities such as the Abrahamic God as MCI agents, but the SM is also supposed to be a theory about what sorts of concepts are transmitted from person to person. And what is transmitted from person to person are verbally expressed explicit representations. Among Muslims, Christians, and Hindus, explicit representations are of a highly counterintuitive God(s). If that is the case, then the SM, as it is usually formulated, can at best claim to be a theory about how explicit god concepts are implicitly represented, not what kinds of concepts are actually culturally transmitted, or enjoy a transmission advantage.

Whitehouse (2002, 2004) distinguishes two "modes” of religiosity. The "imagistic mode" involves the performance of infrequent, high-arousal rituals that make a deep impression that is encoded in episodic memory. These rituals stimulate participants to ruminate about their 
meaning, causing them to experience private revelations about their deeper religious significance—what Whitehouse terms “spontaneous exegetical reflection.” In contrast, the "doctrinal mode" involves the performance of frequent, low-arousal rituals that are to a large extent encoded as procedural knowledge. In the doctrinal mode, people tend to learn rituals by rote and perform them out of habit. Low-arousal, high-frequency rituals tend not to trigger the private revelations brought about by spontaneous exegetical reflection. This leaves an opening for religious experts to supply their own interpretations of rituals to the participants, and to drill these interpretations into their mind through repetition. In Whitehouse's view, religion in either mode tends not to conform to the easy-to-remember, MCI "cognitive optimum position."

Whitehouse notes that Boyer's (2001) theory (i.e., the SM) predicts that the religious concepts of "preliterate, localized traditions" should tend to fall around the cognitive optimum position, and to be radically different from the beliefs of the literate priests. The prediction is not borne out. He says:

Detailed ethnographic evidence on a great range of small-scale nonliterate cultures strongly suggests otherwise. Australian Aboriginal ideas about the "dreamtime” or (“dreaming”) provide a good case in point. Extensive direct study of these traditions has revealed the presence of dauntingly elaborate bodies of philosophical and cosmological knowledge that require many years of intensive contemplation to develop and mature.... Similar [findings] have been made with regard to the cosmologies of small-scale, nonliterate societies in Amazonia..., Africa..., and Melanesia....The overall impression from ethnographic research is that nonliterate societies, in general, do not deal in 
religious concepts that are closer to the cognitive optimum than those of literate societies. (Whitehouse, 2004, pp. 79-80)

Without the right kinds of social support, both imagistic and doctrinal religions will tend to drift toward concepts and practices that are closer to the cognitive optimum (pp. 76, 135).

Nevertheless, societies under all conditions in which humans live tend to gravitate toward religiosity in one or the other (or sometimes even a combination) of these modes. "[R]eligion is...a domain of human thought and action that typically struggles against the constraints of intuitive cognition” (p. 169). MCI concepts like ghosts and magic rivers are also found across societies, but there is more than that to the religions of even preliterate hunter-gatherers that lack anything like a professional priestly caste.

The question, then, is why imagistic and doctrinal modes of religiosity are such powerful “attractor positions” (Sperber, 1996) when they are both counterintuitive, hence inherently less believable (cf. Pyysiäinen, 2003, pp. 112-113), and violate too many of our innate ontological assumptions to have any special resonance with our mind or enjoy a memory advantage. The fact that these religious ideas are endorsed by authorities who demonstrate CREDs, as Henrich argued, is part of the story. But what makes authorities all over the world in every human society independently promulgate such ideas, and what makes people accept the claims of these authorities rather than others who may also exhibit CREDs?

Whitehouse (2002) notes that doctrinal religions are typically "associated with highly developed forms of rhetoric and logically integrated theology” (p. 298). This is the result of selection on techniques of oration over time. People believe in doctrines that are "persuasive.” If conditions are right for religious experts to spread standardized doctrines (namely, people engage 
in routinized rituals that do not trigger too much spontaneous exegetical reflection), the most persuasive ideas will tend to be preserved and to proliferate. The religious doctrines and the techniques for disseminating and reinforcing them that survive the competition will often be able to spread outside the group where they originally developed, thus creating large, anonymous communities of coreligionists.

To understand why certain god concepts, such as those of Abrahamic and Hindu traditions, have become so popular, it may be necessary consider why many people come to think that these concepts are logical and explanatorily powerful. Even if people often employ theologically incorrect concepts in online reasoning, the fact that they explicitly endorse, transmit, and are sometimes even "willing to lay down their lives to preserve and defend” (Whitehouse, 2004, p. 151) these explicit concepts and the practices based on them means that theologically correct beliefs are more than a superficial aspect of religion.

\section{Religious authority and the logical development of doctrine: An explanation of parallel god concepts}

There is no doubt that lay believers in religions like Christianity have different explicit God concepts than educated theologians. This is because the sophisticated, abstract God concepts that theologians possess are difficult to acquire. The concepts are built on philosophical ideas that require time, training, motivation, and a certain amount of intellectual talent to grasp. But if lay believers' ignorance of the recondite doctrines of their religion is, as suggested earlier, analogous to the average American’s ignorance of engineering, it is misleading to identify laypeople’s true (explicit) religious beliefs with those that they can report in a test or survey. Accepting the 
authority of certain religious experts—deferring to their judgment in religious matters, acknowledging that one's own understanding is inferior to that of the experts—is an important element of religiosity. Fully explaining religion requires explaining how people come to accept certain religious authorities.

Even though the explicit religious beliefs of laypeople are less sophisticated than those of theologians, advocates of the SM have not provided convincing evidence that the most successful lay beliefs are actually MCI (Whitehouse, 2004). Though SM theorists claim that children and adults come to implicitly represent God as having humanlike limitations, Christian, Muslim, and Hindu adults do not teach their children that God can (e.g.) only answer one prayer at a time. Rather, they teach their children things like "God can do anything." What is explicitly transmitted is highly counterintuitive. Even if minimally counterintuitive concepts have a transmission advantage in certain contexts, this does not seem to be the explanation for religion in general.

If the arguments in this paper are right, the way to better explain certain aspects of religion is to discover the properties that make propositions in general—not religious propositions specifically—seem credible to us. Virtually no one above age 12 believes in Santa Claus. As discussed above, Barrett himself acknowledges that the reason may be (at least in part) because we learn at a certain point that there is no compelling evidence for Santa's existence-in Barrett's words: “[Santa’s] alleged activities...may be more simply explained by appealing to parents.” The explanation for why people adopt beliefs is not necessarily that the beliefs conform to a special template. It may be that they see those beliefs as being justified. Sometimes religious, rather than naturalistic, propositions might be perceived as "simpl[er]" explanations of important phenomena. 
It seems that people are persuaded to accept doctrinal religions by a combination of the plausibility of what they can understand and the intellectual credibility of the experts who preserve esoteric knowledge and speak with authority on doctrine. The cognitive mechanisms that underlie this process are the same as those that lead untrained Americans to hold certain beliefs (or intuitions) about physics while acknowledging that the beliefs of physicists are more likely to be correct and deferring to recognized authorities when a collective decision must be made that is related to their domain of expertise.

Abstract religious ideas are developed by the application of System 2 reasoning to more or less intuitive premises. System 2 reasoning is conscious, effortful, and difficult. Without a deliberate commitment to engage System 2, people tend to revert to intuitive, System 1 reasoning (Kahneman, 2011). The most successful religions today in terms of numbers of adherentsChristianity, Islam, Hinduism, and Buddhism — teach ideas that were developed over the course of thousands of years. Some of these abstract ideas may, through learning, be encoded in our minds as schemas that thereby become intuitive and incorporated into System 1 (see Purzycki \& Willard, 2016), but some theological ideas are far too abstract for this (e.g., the Christian Trinity or ways to reconcile free will and divine providence). Under conditions that do not conduce to System 2 thinking, people are sure to revert to the intuitive theological beliefs that have been studied by mainstream CSR (cf. Slone, 2004). But cultural transmission does not generally occur under those conditions. Parents and teachers impart to children explicit beliefs that they learned and comprehended (more or less accurately) by means of System 2.

The idea that explicit religious concepts proliferate because people find them logically compelling could explain certain parallels among separately developed religious traditions. For example, Slone (2005) shows that there are striking parallels in the theological debates 
reconciling free will and God's omnipotence in Christianity, Islam, Hinduism, and Buddhism. In each of these traditions, theologians recognized a tension between our experience of free human agency and the postulated existence of powerful (or all-powerful) gods, particular creator gods. In each tradition, theologians advocated three kinds of approaches: (a) free will is real, (b) the power of god(s) precludes the possibility of free will, or (c) a “combinatorial position” allowing for the limited exercise of free will within constraints imposed by God(s).

Slone explains these parallel developments as the consequence of applying "implicational logic” to religious systems. When religion takes on the doctrinal mode, theologians must make the system logically coherent in order to persuade large numbers of people to accept it (see Whitehouse, 2004, p. 123). Because doctrinal religions tend to spread among large number of people in different populations, Slone argues that it is necessary to attribute more and more power to God(s) in order for him to take on his growing responsibilities. This eventually leads to the premise that God is all powerful, which, in conjunction with our experience-based belief in free will, generates a paradox. The logic of the paradox allows for only a few possible solutions, so it was inevitable that the same variety of approaches would be taken in different traditions.

As another example, take the concept of the creator in Judaism and Hinduism. Both religions hold that the world was created by a divine agent. This generated a problem, namely, if the world was created, why did the creator not need to be created? Theologians in both traditions solved the problem in analogous ways.

The names of God in Judaism and Hinduism convey the same philosophical message, namely, that God's existence is fundamentally different from that of anything in the creation. The principle name of God in Judaism (YHWH) is derived from the Hebrew verb "to be," indicating that "being" is an intrinsic part of his nature. The creator in Hinduism is called 
Svayambhu, meaning “self-existent” or "self-causing," conveying virtually the same idea (see Manusmrti, 1886, 1.3-4, 1.7).

Both Judaism and Hinduism hold that the creator's essence is incomprehensible, though he (or it) chooses to reveal certain aspects of his nature in such a way that we can comprehend it. Although his nature is beyond comprehension, his manifestation in the world can be understood and described to some extent in human terms. According to Jewish tradition, we cannot know or say anything about God's nature, but we can talk about his actions, or will-that is to say, the principles by which he runs the world (Luzzatto, 1735/1998, opening 1; Maimonides, 1190/1963, 1.54). So, for example, we can know that God punishes the wicked and rewards the righteous. We can also say that he hates the wicked and loves the righteous. He does not actually experience the emotions of love and hate, but we can describe his actions as if they were motivated by humanlike emotions.

Hindu theologians distinguish Nirguna (“attributeless”) from Saguna (“with qualities”) Brahman (God). Nirguna Brahman is the true, incomprehensible form of Brahman, and it is described only as what it is not, or in contradictory terms, i.e., "Brahman is X and not-X.” A famous passage in the Brihadāranyaka Upanishad says: "Now, therefore, the description of Brahman: 'Not this, not this'; for there is no other and more appropriate description than this 'Not this’” (2.3.6). In contrast, Saguna Brahman can be described with regular adjectives. Jewish and Hindu sources use almost identical analogies to illustrate the relationship between God's unknowable essence and his knowable worldly manifestations. Maimonides (1190/1963) explains: “[T]hough an agent is one, diverse actions may proceed from him, even if he does not possess will and all the more if he acts through will.” A fire has different effects on different things: "it melts some things, makes others hard, cooks and burns, bleaches and 
blackens....[But fire] performs all these actions by virtue of one active quality, namely, heat” (1.53). In the same way, God is a single, unchanging entity, but manifests in the world in seemingly different ways at different times. The Katha Upanishad says that, though Brahman is an unchanging, unconflicted being, he manifests in the world through individuals atmans (souls), causing a variety of different effects, like "the same non-dual fire...becomes different according to whatever it burns” (2.2.9). The Upanishad continues: “There is one Supreme Ruler, the inmost Self of all beings, who makes His one form manifold” (2.2.12).

Both Judaism and Hinduism teach that time itself is part of God's creation. The Jewish commentator Nachmanides derives this from the biblical verse, "Because six days (sic) God created the heavens and the earth...”-not in six days God created the heavens and the earth, but God created six days, the heavens, and the earth (Nachmanides, 13th century/1974, on Exodus 20:11). The Hindu lawgiver Manu says: “Time and the divisions of time, the lunar mansions and the planets, the rivers, the oceans, the mountains, plains, and uneven ground,...this whole creation he [Svayambhu] likewise produced, as he desires to call these beings into existence” (Manusmrti, 1886, 1.24-25). Judaism and Hinduism explain God's relationship with time in the same way: He is both outside and inside time. His true essence is beyond time, but in his capacity of supervisor of the world in Judaism, or Saguna Brahman in Hinduism, he is in time. ${ }^{7}$

The forgoing, extremely abbreviated overview of how God is conceived in Judaism and Hinduism does not, of course, begin to do justice to the exceedingly complicated philosophical discussion in these traditions carried out over the course of thousands of years. But some broad

\footnotetext{
${ }^{7}$ Christian theologians followed a different line of reasoning and concluded that God is outside of time (Augustine, 397-400/1998).
} 
parallels clearly do exist between the traditions. The point of drawing attention to this is as follows. To really understand how God is conceived in a religion like Judaism or Hinduism requires intensive study, which not all followers have the opportunity to undertake. The average believer will necessarily have a distorted understanding of the sophisticated God concept possessed by the elites, and will have virtually no understanding of the philosophical niceties of the concept that were worked out over the centuries or even millennia. Yet somehow believers in different traditions come to attach themselves to authorities who develop ideas using the same principles of logic. As a result, theologians in different traditions may reach parallel conclusions, or follow different lines of reasoning and deviate from each other in semi-predictable ways. This is a religious phenomenon that requires explanation, and it cannot be illuminated only by studying the implicit or explicit God concepts of typical believers.

\section{Acknowledgements}

Thanks to Marta Halina, Neven Sesardić, and three reviewers for Philosophical Psychology for helpful comments on earlier drafts of this paper.

\section{References}

Atran, S. (2002). In gods we trust: The evolutionary landscape of religion. Oxford: Oxford University Press. 
Atran, S., \& Henrich, J. (2010). The evolution of religion: How cognitive by-products, adaptive learning heuristics, ritual displays, and group competition generate deep commitments to prosocial religions. Biological Theory, 5, 18-30.

Augustine. (1998). Confessions (H. Chadwick, Trans.). Oxford: Oxford University Press. (Original work published 397-400)

Banerjee, K., Haque, O. S., \& Spelke, E. S. (2013). Melting lizards and crying mailboxes: Children’s preferential recall of minimally counterintuitive concepts. Cognitive Science, 37, 1251-1289.

Barrett, J. L. (1998). Cognitive constraints on Hindu concepts of the divine. Journal for the Scientific Study of Religion, 37, 608-619.

Barrett, J. L. (1999). Theological correctness: Cognitive constraint and the study of religion. Method \& Theory in the Study of Religion, 11, 325-339.

Barrett, J. L. (2000). Exploring the natural foundations of religion. Trends in Cognitive Sciences, 4, 29-34.

Barrett, J. L. (2004). Why would anyone believe in god? Walnut Creek, CA: AltaMira Press.

Barrett, J. L. (2007). Cognitive science of religion: What is it and why is it? Religion Compass, $1,768-786$.

Barrett, J. L. (2008). Why Santa Claus is not a god. Journal of Cognition and Culture, 8, 149161.

Barrett, J. L., \& Keil, F. C. (1996). Conceptualizing a nonnatural entity: Anthropomorphism in god concepts. Cognitive Psychology, 31, 219-247.

Barrett, J. L., \& Lanman, J. A. (2008). The science of religious beliefs. Religion, 38, 109-124. 
Barrett, J. L., \& Nyhof, M. A. (2001). Spreading non-natural concepts: The role of intuitive conceptual structures in memory and transmission of cultural materials. Journal of Cognition and Culture, 1, 69-100.

Boyer, P. (2001). Religion explained: The evolutionary origins of religious thought. New York: Basic Books.

Boyer, P. (2003). Religious thought and behaviour as by-products of brain function. Trends in Cognitive Sciences, 7, 119-124.

Boyer, P. (2005). A reductionist model of distinct modes of religious transmission. In H. Whitehouse \& R. N. McCauley (Eds.), Mind and religion: Psychological and cognitive foundations of religiosity (pp. 3-30). Walnut Creek, CA: AltaMira Press.

Boyer, P., \& Bergstrom, B. (2008). Evolutionary perspectives on religion. Annual Review of Anthropology, 37, 111-130.

Boyer, P., \& Ramble, C. (2001). Cognitive templates for religious concepts: Cross-cultural evidence for recall of counter-intuitive representations. Cognitive Science, 25, 535-564.

Bulbulia, J. (2004). The cognitive and evolutionary psychology of religion. Biology \& Philosophy, 19, 655-686.

Dennett, D. C. (2006). Breaking the spell: Religion as a natural phenomenon. New York: Viking.

Gervais, W. M., \& Henrich, J. (2010). The Zeus problem: Why representational content biases cannot explain faith in gods. Journal of Cognition and Culture, 10, 383-389.

Harris, P. L., \& Koenig, M. A. (2006). Trust in testimony: How children learn about science and religion. Child Development, 77, 505-524. 
Henrich, J. (2009). The evolution of costly displays, cooperation and religion: Credibility enhancing displays and their implications for cultural evolution. Evolution and Human Behavior, 30, 244-260.

Henrich, J. (2016). The secret of our success: How culture is driving human evolution, domesticating our species, and making us smarter. Princeton, NJ: Princeton University Press.

Jaswal, V. K. (2010). Believing what you're told: Young children's trust in unexpected testimony about the physical world. Cognitive Psychology, 61, 248-272.

Kahneman, D. (2011). Thinking, fast and slow. New York: Farrar, Straus and Giroux.

Knobe, J. (2010). Person as scientist, person as moralist. Behavioral and Brain Sciences, 33, 315-329.

Lawson, E. T. (1999). Religious ideas and practices. In R. A. Wilson \& F. C. Keil (Eds.), The MIT encyclopedia of the cognitive sciences (pp. 720-721). Cambridge, MA: MIT Press.

Luzzatto, M. C. (1998). [Derech Hashem] The way of God (6th ed., A. Kaplan, Trans.). Jerusalem: Feldheim. (Original work published 1735)

Maimonides, M. (1963). The guide of the perplexed (S. Pines, Trans.). Chicago: University of Chicago Press. (Original work published 1190)

[Manusmrti] The laws of Manu. (1886). (F. M. Müller, Trans.). Oxford: Clarendon Press. Nachmanides. (1974). Commentary on the Torah: Leviticus (C. B. Chavel, Trans.). New York: Shilo Publishing House. (Original work published 13th century)

Norenzayan, A., Atran, S., Faulkner, J., \& Schaller, M. (2006). Memory and mystery: The cultural selection of minimally counterintuitive narratives. Cognitive Science, 30, 531-553. Purzycki, B. G., \& Willard, A. K. (2016). MCI theory: A critical discussion. Religion, Brain \& Behavior, 6, 207-248. 
Pyysiäinen, I. (2003). True fiction: Philosophy and psychology of religious belief. Philosophical Psychology, 16, 109-125.

Pyysiäinen, I. (2012). Putting cognition and culture back together again: Religion in mind and society. Method \& Theory in the Study of Religion, 24, 29-50.

Richerson, P. J., \& Boyd, R. (2005). Not by genes alone: How culture transformed human evolution. Chicago: University of Chicago Press.

Russell, Y. I., \& Gobet, F. (2013). What is counterintuitive? Religious cognition and natural expectation. Review of Philosophy and Psychology, 4, 715-749.

Shtulman, A. (2008). Variation in the anthropomorphization of supernatural beings and its implications for cognitive theories of religion. Journal of Experimental Psychology: Learning, Memory, and Cognition, 34, 1123-1138.

Shtulman, A. (2017). Scienceblind: Why our intuitive theories about the world are so often wrong. New York: Basic Books.

Slone, D. J. (2004). Theological incorrectness: Why religious people believe what they shouldn't. New York: Oxford University Press.

Slone, D. J. (2005). Why religions develop free-will problems. In H. Whitehouse \& R. N. McCauley (Eds.), Mind and religion: Psychological and cognitive foundations of religiosity (pp. 187-206). Walnut Creek, CA: AltaMira Press.

Sperber, D. (1996). Explaining culture: A naturalistic approach. Oxford: Blackwell. [Upanishads] The Upanishads. (1964). (Swami Nikhilananda, Trans.). New York: Harper Torchbooks.

Whitehouse, H. (2002). Modes of religiosity: Towards a cognitive explanation of the sociopolitical dynamics of religion. Method \& Theory in the Study of Religion, 14, 293-315. 
Whitehouse, H. (2004). Modes of religiosity: A cognitive theory of religious transmission. Walnut Creek, CA: AltaMira Press.

Willard, A. K., Henrich, J., \& Norenzayan, A. (2016). Memory and belief in the transmission of counterintuitive content. Human Nature, 27, 221-243. 